\title{
BMJ Open Association between alcohol drinking behaviour and cognitive function: results from a nationwide longitudinal study of South Korea
}

\author{
Sujin Kim, ${ }^{1}$ Yongjoo Kim, ${ }^{2}$ Sang Min Park ${ }^{1,3}$
}

To cite: Kim S, Kim Y, Park SM. Association between alcohol drinking behaviour and cognitive function: results from a nationwide longitudinal study of South Korea. BMJ Open 2016;6:e010494. doi:10.1136/bmjopen-2015010494

- Prepublication history for this paper is available online. To view these files please visit the journal online (http://dx.doi.org/10.1136/ bmjopen-2015-010494).

Received 9 November 2015 Revised 29 February 2016 Accepted 7 April 2016

CrossMark

\footnotetext{
${ }^{1}$ Takemi Program in International Health, Harvard T. H. Chan School of Public Health, Boston,

Massachusetts, USA

${ }^{2}$ Department of Social and Behavioral Sciences, Harvard T. H. Chan School of Public Health, Boston,

Massachusetts, USA

${ }^{3}$ Department of Family Medicine \& Department of Biomedical Sciences, Seoul National University College of Medicine, Seoul, South Korea

Correspondence to Dr Sang Min Park; smpark.snuh@gmail.com
}

\section{ABSTRACT}

Objectives: This research intends to determine how drinking behaviour, such as episodic heavy drinking, is related to cognitive performance in middle-aged and old-aged people in South Korea.

Methods: A cohort data of 5157 adults, age 45 years or older, with normal cognitive function (the Korean version of the Mini-mental state examination (K-MMSE) $\geq 24$ ) at baseline (2006), was derived from the Korean Longitudinal Study of Aging. Alcohol drinking behaviour was assessed using the CAGE (Cut down, Annoyed, Guilty, Eye-opener) questionnaire. The relationships between baseline drinking behaviour (in 2006) to the extent of cognitive decline (between 2006 and 2012) and development of cognitive impairment (in 2012) were assessed.

Results: Individuals with problematic drinking behaviour at baseline experienced a faster decline in cognitive function than those with non-problematic drinking $(p<0.05)$ during 6 years of follow-up, especially among those with relatively lownormal K-MMSE score $(24-26)$ at baseline $(p<0.05)$.

Problematic alcohol drinking behaviour was also significantly associated with onset of severe cognitive impairment (SCI) (K-MMSE score $\leq 17)$ among those with relatively low-normal K-MMSE score (adjusted OR $(\mathrm{aOR})=3.76,95 \% \mathrm{Cl} 1.46$ to 9.67$)$. In addition, abstinence, compared with non-problematic drinking, was related to higher risk for developing $\mathrm{SCl}$ among men (aOR=1.62, 95\% Cl 1.09 to 2.39).

Conclusions: Our results suggest that those with problematic alcohol drinking behaviour could be at an increased risk of cognitive impairment/decline. While further research will provide stronger evidence, intervention targeting alcohol abuse may play a role in prevention of cognitive impairment.

\section{INTRODUCTION}

Along with demographic transition, cognitive impairment is increasing globally. ${ }^{1}$ For example, as of 2010, approximately 36 million people worldwide have dementia, and the number is projected to nearly

\section{Strengths and limitations of this study}

- This is the first study to explore the relationship between drinking behaviour, such as nonproblematic or episodic heavy drinking, and cognitive decline/impairment in an Asian population.

- A nationally representative prospective survey of Korean adults aged 45 years or older was used.

- To address the issue of reverse causation in observational studies, we limited study participants to those with normal cognitive function at baseline as well as adjusted for baseline cognitive score.

- Since a self-reported measure of alcohol drinking behaviour was used, it is possible for participants to under-report their drinking behaviours.

double every 20 years, to 66 million in 2030 and to 115 million in $2050 .{ }^{2}$ Given that a cure for dementia and cognitive impairment has been elusive, as well as the fact of recent rising burden of the disease, there is a crucial need to identify modifiable risk factors associated with cognitive impairment.

The protective effects of light-to-moderate alcohol consumption against cognitive impairment have been widely reported ${ }^{3-5}$ along with detrimental effects of heavy alcohol consumption. ${ }^{6}$ While most of the findings are from western countries including Western Europe and the USA, conflicting results have been reported in other regions, such as Eastern Europe and Asian countries; for instance, no significant association between heavy alcohol consumption and cognitive impairment was observed among Eastern European adults, ${ }^{7}$ or linear negative relationships between alcohol consumption and cognitive function were reported among South Korean adults. ${ }^{8}$ These discrepancies between different studies may be explained not only by heterogeneity in the population but also by differences in baseline cognitive performance, differences in follow-up period 
and reverse-causality, such as abstinence due to health problems.

Meanwhile, since existing literature focuses on mean alcohol intake, little is known about the relationship between drinking patterns, such as alcohol use disorders, to cognitive impairment. ${ }^{7} 9{ }^{10}$ For example, a history of problematic alcohol drinking (PrAD) may not simply reflect current heavy mean alcohol consumption, ${ }^{9}$ and in itself may be indicative of alcohol-related brain damage, metabolic changes in the brain, ${ }^{11}$ and nutritional deficiency, ${ }^{12}$ which result in dementia and cognitive impairment in later life. Few studies, however, have investigated the causal relationship between the history of alcohol use disorders and the risk of cognitive impairment. $^{79} 10$

Alcohol consumption is not unusual in South Korea (hereafter Korea). In 2010, persons aged 15 years or older drank, on average, $12.3 \mathrm{~L}$ of pure alcohol per year in Korea, which is almost double the worldwide consumption of $6.2 \mathrm{~L}$. The levels of alcohol consumption in Korea are particularly higher among men than women $(21.0$ vs $3.9 \mathrm{~L})$, whereas they were at 12.3 vs $2.9 \mathrm{~L}$ in the world's population. In addition, the prevalence of alcohol use disorders (including alcohol dependence and harmful use of alcohol) was $6.2 \%$ in Korea (10.3\% for men and $2.2 \%$ for women), which was higher than worldwide prevalence of $4.1 \%$ ( $7.2 \%$ for men and $1.3 \%$ for women). ${ }^{13}$ While common social and business drinking may contribute to high alcohol consumption, traditional norms against female drinking may be related to the significant gender difference. ${ }^{44}$ Moreover, high alcohol consumption is attributable to more years of life lost in Korea. ${ }^{13}$

In light of this context, this study intends to investigate whether/how drinking patterns such as non-problematic drinking and episodic heavy drinking play a role in the development of severe cognitive impairment (SCI), and the extent to which drinking patterns influence the decline in cognitive performance, by using a nationally representative longitudinal sample of Korean middle-aged and old-aged adults with normal cognitive function at baseline.

\section{METHODS}

\section{Study population}

Data was taken from the Korean Longitudinal Study of Aging (KLoSA), administered by the Korea Labor Institute. KLoSA is a nationally representative panel study of middle-aged and old-aged household-dwelling adults in Korea. Basing on area (urban/rural) and type of housing (apartment/ordinary housing), $1000 \mathrm{enu}-$ meration districts (EDs) were sampled. Approximately six households within each ED were randomly selected, which, in turn, resulted in a total of 6171 households and 10254 individuals (aged 45 years or older) sampled at baseline (2006). The survey has been conducted every even-numbered year, starting from 2006, thereby currently providing publicly available data with a total of four waves (2006, 2008, 2010 and 2012). At each wave, data regarding health status, income, assets, employment and subjective expectation were collected. The follow-up rate per each wave was $86.6 \%$, $80.3 \%$ and $76.2 \%$ for the 2008, 2010 and 2012 survey, respectively. ${ }^{15}$ Since anonymous KLoSA data, which is publicly available in the website (http://survey.keis.or. $\mathrm{kr} /$ ), was used, institutional review board approval was waived for this study.

For the study, of 10254 individuals, for whom cognitive function was assessed at baseline (2006), 7299 individuals with normal cognitive function (the Korean version of the Mini-mental state examination (K-MMSE) $>23$ ) were selected as baseline study population. ${ }^{16}$ Individuals numbering 1763 were excluded from the fourth wave (330 due to death, 1433 due to nonresponse). Of 5536 individuals, after excluding 379 individuals with at least one missing value for independent variables used in this study, a total of 5157 respondents were investigated as our analytic sample.

\section{Outcome measures}

This study measured cognitive function by using K-MMSE scores. The MMSE is a simple instrument developed to measure global cognitive performance and help screen for dementia. The MMSE questionnaire consists of 11 items in seven categories of cognitive functions including orientation for time, orientation for place, registration of three objects, attention and calculation, recall of three words, language and visual construction. ${ }^{16} 17$ The total score of the measure ranged from 0 to 30 . The validity of the K-MMSE has been reported elsewhere. ${ }^{17}$ The measurement defines mild cognitive impairment (MCI) as scoring 23 point or less, and SCI as scoring 17 point or less. ${ }^{16} 17$ For this study, the onset of SCI (K-MMSE $\leq 17$ ) and change in K-MMSE scores over a 6 year follow-up were employed as outcome measures.

\section{Drinking status}

Drinking behaviour was categorised into four groups: No alcohol drinking (NAD), past alcohol drinking $(\mathrm{PaAD})$, non-problematic alcohol drinking (NPAD), and PrAD. We distinguished non-problematic drinking from PrAD based on the CAGE (acronym referring to four questions, see below) questionnaire, which is an assessment instrument widely used for identifying alcoholics. ${ }^{18}$ The questionnaire includes the following questions: 'Have you ever felt you ought to Cut down on your drinking?'; 'Have people Annoyed you by criticizing your drinking?'; 'Have you ever felt bad or Guilty about your drinking?'; 'Have you ever had a drink first thing in the morning to steady your nerves or to get rid of a hangover (Eye opener)?' The respondent answering 'yes' for at least two of the CAGE questions was considered to have problematic drinking behaviour. The other drinkers answering 'yes' for one or none of the 
questions were defined as having NPAD behaviour. In addition, NAD indicated that a respondent never had a drink; PaAD identified that a respondent used to drink, but has quit drinking. In all analyses, NPAD was used as the reference group.

\section{Covariates}

All covariates were collected from the 2006 survey. The sociodemographic variables include age groups (45-54; 55-64 and 65 years or older); gender (female or male), marital status (married or single); educational status (elementary school, middle school, high school, or college or more); equivalised household income quartile (the poorest, second, third or the wealthiest quartile); health insurance status (the National Health Insurance or Medicaid) and living places (rural or urban). Other health behaviours, such as smoking (ever or never smokers) and physical activity (at least once a week or no) were identified as dummy variables. In addition, health status was assessed using three dummy variables as follows: chronic disease ( $\geq 1$ or none), activities of daily living (ADL) ( $\geq 1$ or none) and depressive symptoms based on the Center for Epidemiological Studies Depression Scale 10 scale $\left(\geq 4\right.$ or $<4$ symptoms). ${ }^{19}$ To address the issue of reverse causation, baseline MMSE was used as a covariate besides limiting study participants to those with normal cognitive function at baseline.

\section{Statistical analysis}

We estimated adjusted means of change in K-MMSE score and adjusted ORs (aORs) of the development of SCI by using linear regressions and logistic regressions, respectively. For each outcome, starting from model 1 adjusting age and gender, we sequentially added a set of covariates. Model 2 further adjusted for sociodemographic characteristics including marital status, educational levels, household income, health insurance status and living place, in addition to age and gender. Model 3 added health behaviours, such as exercise and smoking status, and chronic disease status in model 2. In model 4, baseline K-MMSE score, ADL and depression status were further adjusted based on model 3 .

After investigating the overall association of drinking behaviour with each outcome, subgroup analyses were performed with respect to factors including baseline K-MMSE scores (24-26 as lower normal and 27-30 as higher $n$ ormal), age ( $<65$ years and $\geq 65$ years), gender, education $(<$ college and $\geq$ college), income $(<50$ th and $\geq 50$ th centiles), living area (urban and rural), smoking (ever and never smokers), physical activity, BMI $(<25$ and $\geq 25 \mathrm{~kg} / \mathrm{m}^{2}$ ) and comorbidity $(0$ and $1+)$. We applied longitudinal sampling weight for the first (2006) and fourth (2012) waves, and adjusted for design effect to correct for SEs. For all analyses, Stata (V.12.0/SE) was used, and level of significance was set as 0.05 (two-sided).

\section{RESULTS}

\section{Descriptive statistics}

Table 1 presented the baseline characteristics of the study participants, Korean adults aged 45 years or older $(\mathrm{N}=5157)$. The proportion of current drinkers was greater in younger age groups; $48.5 \%, 40.7 \%, 33.3 \%$ for $\mathrm{NPAD}$, and $4.3 \%, 4.3 \%, 2.8 \%$ for PrAD among those aged $45-54,55-64$ and $\geq 65$ years, respectively. The majority of men were current drinkers (NPAD 63.2\%, PrAD 7.3\%), while these proportions were much smaller among women (NPAD 23.5\%, PrAD 0.6\%).

\section{Association of drinking behaviour with change in cognitive performance}

Figure 1 presents the association between drinking behaviour and change in cognitive function both for all individuals and stratified by K-MMSE scores at baseline. Among all participants $(\mathrm{N}=5157)$, baseline drinking behaviours were statistically significantly associated with a change in cognitive function over the follow-up period. When compared with NPAD, PrAD was associated with, on average, a 1.30 point $(95 \%$ CI 0.08 to 2.52) greater decline in K-MMSE score over the follow-up period in the fully adjusted model.

The magnitude of the association was even greater among individuals with normal but relatively lower K-MMSE scores at baseline $(\beta=-3.28,95 \%$ CI -6.14 to -0.42 ), while the association was not statistically significant among those with relatively higher K-MMSE scores at baseline $(\beta=-0.51,95 \% \mathrm{CI}-1.72$ to -0.69$)$.

Figure 2 presents the results from subgroup analyses for the association between drinking behaviour and change in cognitive function with respect to gender, age, income, education, BMI, smoking, physical activity, place of living and chronic disease status at baseline in our fully adjusted model. When compared to men with NPAD, men with PrAD at baseline experienced greater decline in K-MMSE score points $(\beta=-1.54,95 \%$ CI -2.83 to -0.25$)$, while the association was not significant among females $(\beta=-0.01,95 \% \mathrm{CI}-4.23$ to 4.21$)$. In addition, among individuals with at least one chronic disease at baseline, PrAD led to greater reduction in cognitive function when compared to NPAD $(\beta=-3.57$, $95 \%$ CI -6.14 to -1.00 ), while there was no significant evidence of association among those without chronic disease at baseline ( $\beta=0.21,95 \%$ CI -0.73 to 1.15 ).

\section{Association of drinking behaviour with SCI}

Table 2 presents the association between drinking behaviour and SCI both among all individuals, and stratified by K-MMSE scores at baseline. Among all study participants $(\mathrm{N}=5157)$, there was no statistically significant evidence of association between types of alcohol drinking at baseline and development of SCI (K-MMSE $\leq 17$ ) after the 6 year follow-up period.

However, among individuals with normal but relatively low cognitive function $(24 \leq \mathrm{K}-\mathrm{MMSE}$ score $\leq 26)$ at baseline $(n=1564)$, there was statistically significant evidence 
Table 1 Baseline sociodemographic characteristics of Korean adults aged 45 years or older according to drinking behaviour

\begin{tabular}{|c|c|c|c|c|c|c|c|c|c|c|c|}
\hline \multirow[b]{2}{*}{ All } & & \multicolumn{2}{|c|}{$\begin{array}{l}\text { No alcohol } \\
\text { drinking }\end{array}$} & \multicolumn{2}{|c|}{$\begin{array}{l}\text { Past alcohol } \\
\text { drinking }\end{array}$} & \multicolumn{2}{|c|}{$\begin{array}{l}\text { Non-problematic } \\
\text { alcohol drinking }\end{array}$} & \multicolumn{2}{|c|}{$\begin{array}{l}\text { Problematic } \\
\text { alcohol } \\
\text { drinking }\end{array}$} & p Value \\
\hline & 5157 & & 2597 & 47.1 & 296 & 50.0 & 2071 & 43.8 & 193 & 4.1 & \\
\hline \multicolumn{12}{|l|}{ Age (years) } \\
\hline $45-54$ & 2128 & 55.7 & 1024 & 43.9 & 66 & 3.3 & 953 & 48.5 & 85 & 4.3 & \multirow[t]{3}{*}{$<0.001$} \\
\hline $55-64$ & 1686 & 28.6 & 860 & 49.3 & 94 & 5.7 & 661 & 40.7 & 71 & 4.3 & \\
\hline $65+$ & 1343 & 15.7 & 713 & 54.5 & 136 & 9.4 & 457 & 33.3 & 37 & 2.8 & \\
\hline \multicolumn{12}{|l|}{ Sex } \\
\hline Male & 2528 & 51.2 & 583 & 21.3 & 258 & 8.2 & 1511 & 63.2 & 176 & 7.3 & \multirow[t]{2}{*}{$<0.001$} \\
\hline Female & 2629 & 48.8 & 2014 & 74.3 & 38 & 1.6 & 560 & 23.5 & 17 & 0.6 & \\
\hline \multicolumn{12}{|l|}{ Marital status } \\
\hline Married & 4515 & 88.4 & 2191 & 45.5 & 265 & 4.9 & 1876 & 45.2 & 183 & 4.4 & \multirow[t]{2}{*}{$<0.001$} \\
\hline Unmarried & 642 & 11.6 & 406 & 59.7 & 31 & 5.1 & 195 & 33.3 & 10 & 1.9 & \\
\hline \multicolumn{12}{|l|}{ Education } \\
\hline Elementary school & 410 & 5.8 & 261 & 63.9 & 30 & 6.8 & 109 & 26.7 & 10 & 2.6 & \multirow[t]{4}{*}{$<0.001$} \\
\hline Middle school & 1334 & 21.9 & 752 & 55.1 & 84 & 5.9 & 449 & 34.3 & 49 & 4.7 & \\
\hline High school & 1014 & 19.8 & 521 & 48.2 & 64 & 5.9 & 385 & 41.7 & 44 & 4.3 & \\
\hline College+ & 2399 & 52.6 & 1063 & 41.6 & 118 & 4.0 & 1128 & 50.5 & 90 & 3.9 & \\
\hline \multicolumn{12}{|l|}{ Household income } \\
\hline $1 \mathrm{Q}$ & 1317 & 22.5 & 689 & 49.3 & 80 & 5.1 & 517 & 43.3 & 31 & 2.4 & \multirow[t]{4}{*}{0.003} \\
\hline $2 \mathrm{Q}$ & 1262 & 23.3 & 637 & 49.1 & 78 & 5.6 & 485 & 39.9 & 62 & 5.3 & \\
\hline $3 Q$ & 1407 & 28.6 & 685 & 44.8 & 86 & 5.2 & 571 & 45.1 & 65 & 4.9 & \\
\hline $4 Q$ & 1171 & 25.6 & 586 & 46.0 & 52 & 4.0 & 498 & 46.5 & 35 & 3.5 & \\
\hline \multicolumn{12}{|l|}{ Insurance } \\
\hline Medicaid & 204 & 3.9 & 108 & 50.6 & 23 & 13.1 & 67 & 33.5 & 6 & 2.8 & \multirow[t]{2}{*}{$<0.001$} \\
\hline National health insurance & 4953 & 96.1 & 2489 & 47.0 & 273 & 4.6 & 2004 & 44.3 & 187 & 4.1 & \\
\hline Location & & & & & & & & & & & \\
\hline Urban & 3965 & 79.8 & 2014 & 47.3 & 213 & 4.6 & 1601 & 44.3 & 137 & 3.8 & 0.081 \\
\hline Rural & 1192 & 20.2 & 583 & 46.6 & 83 & 6.3 & 470 & 42.1 & 56 & 5.0 & \\
\hline Physical activity & & & & & & & & & & & \\
\hline Yes & 2277 & 43.9 & 1090 & 45.0 & 143 & 5.4 & 954 & 45.3 & 90 & 4.4 & 0.069 \\
\hline No & 2880 & 56.1 & 1507 & 48.9 & 153 & 4.6 & 1117 & 42.7 & 103 & 3.8 & \\
\hline Ever smoking & & & & & & & & & & & \\
\hline No & 3525 & 66.5 & 2324 & 63.1 & 126 & 3.2 & 1035 & 32.5 & 40 & 1.3 & $<0.001$ \\
\hline Yes & 1632 & 33.5 & 273 & 15.5 & 170 & 8.5 & 1036 & 66.3 & 153 & 9.7 & \\
\hline ADL & & & & & & & & & & & \\
\hline 0 & 5116 & 99.3 & 2574 & 47.1 & 291 & 4.9 & 2060 & 43.9 & 191 & 4.1 & 0.111 \\
\hline $1+$ & 41 & 0.7 & 23 & 47.9 & 5 & 13.6 & 11 & 35.6 & 2 & 3.0 & \\
\hline Comorbidity & & & & & & & & & & & \\
\hline 0 & 3026 & 63.3 & 1507 & 46.3 & 111 & 3.2 & 1298 & 46.4 & 110 & 4.1 & $<0.001$ \\
\hline
\end{tabular}



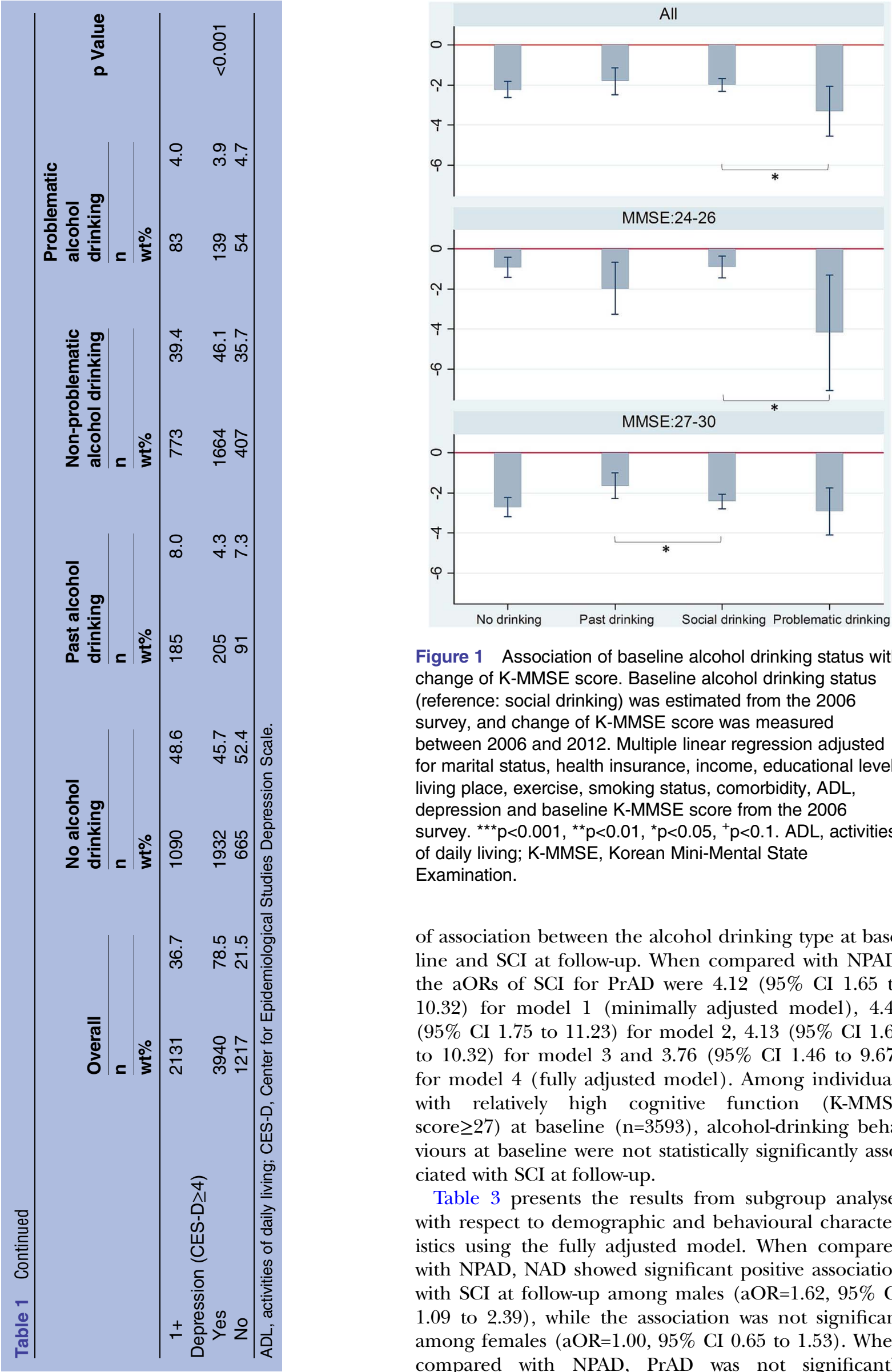

Figure 1 Association of baseline alcohol drinking status with change of K-MMSE score. Baseline alcohol drinking status (reference: social drinking) was estimated from the 2006 survey, and change of K-MMSE score was measured between 2006 and 2012. Multiple linear regression adjusted for marital status, health insurance, income, educational level, living place, exercise, smoking status, comorbidity, ADL, depression and baseline K-MMSE score from the 2006 survey. ${ }^{* *} p<0.001,{ }^{* *} p<0.01,{ }^{*} p<0.05,{ }^{+} p<0.1$. ADL, activities of daily living; K-MMSE, Korean Mini-Mental State Examination.

of association between the alcohol drinking type at baseline and SCI at follow-up. When compared with NPAD, the aORs of SCI for PrAD were 4.12 (95\% CI 1.65 to 10.32) for model 1 (minimally adjusted model), 4.43 (95\% CI 1.75 to 11.23 ) for model 2, 4.13 (95\% CI 1.65 to 10.32 ) for model 3 and 3.76 (95\% CI 1.46 to 9.67) for model 4 (fully adjusted model). Among individuals with relatively high cognitive function (K-MMSE score $\geq 27)$ at baseline $(n=3593)$, alcohol-drinking behaviours at baseline were not statistically significantly associated with SCI at follow-up.

Table 3 presents the results from subgroup analyses with respect to demographic and behavioural characteristics using the fully adjusted model. When compared with NPAD, NAD showed significant positive association with SCI at follow-up among males $(\mathrm{aOR}=1.62,95 \%$ CI 1.09 to 2.39 ), while the association was not significant among females $(\mathrm{aOR}=1.00,95 \%$ CI 0.65 to 1.53$)$. When compared with NPAD, PrAD was not significantly 


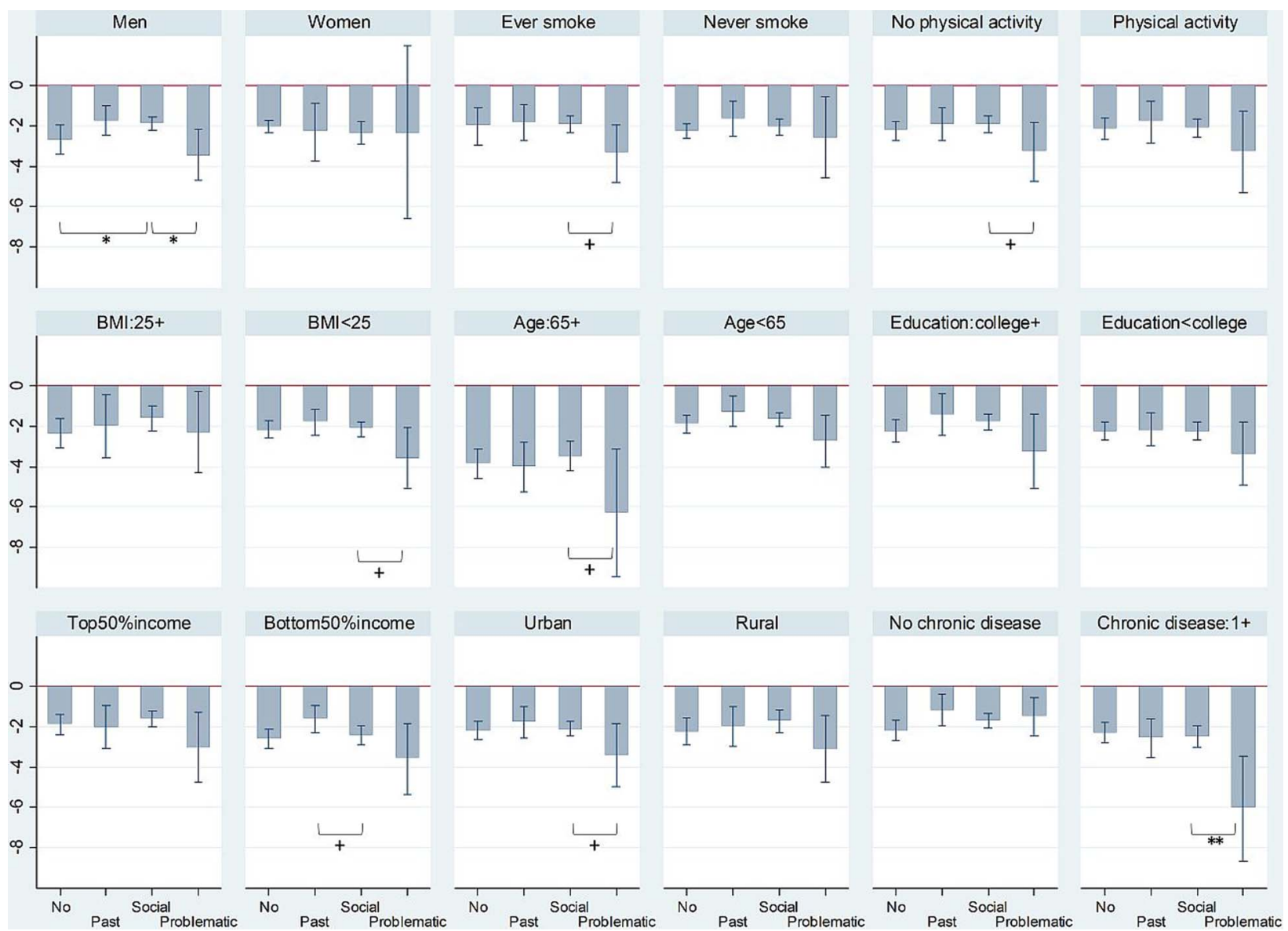

Figure 2 Association of baseline alcohol drinking status with change of K-MMSE score, stratified by demographic and behavioural factors. Baseline alcohol drinking status (reference: social drinking) was estimated from the 2006 survey, and change of K-MMSE score was measured between 2006 and 2012. Multiple linear regression adjusted for marital status, health insurance, income, educational level, living place, exercise, smoking status, comorbidity, ADL, depression and baseline K-MMSE score from the 2006 survey. ${ }^{* *} p<0.001,{ }^{* *} p<0.01,{ }^{*} p<0.05,{ }^{+} p<0.1$. ADL, activities of daily living; BMI, body mass index; K-MMSE, Korean Mini-Mental State Examination.

associated with SCI for both men $(\mathrm{aOR}=1.74,95 \%$ CI 0.86 to 3.53$)$ and women $(\mathrm{aOR}=1.79,95 \%$ CI 0.40 to 8.08). Among those with at least one chronic disease at baseline, PrAD showed significant positive association with SCI at follow-up (aOR=3.60, 95\% CI 1.61 to 8.07).

\section{DISCUSSION}

In this nationally representative cohort study, individuals having PrAD behaviour at baseline experienced faster decline in cognitive function than those with nonproblematic drinking behaviour during a 6 year follow-up period. This pattern was observed in the whole population, being more remarkable in people with relatively low-normal K-MMSE score (24-26) at baseline compared with those with high-normal K-MMSE scores (27-30). In addition, we found that a history of PrAD behaviour was significantly related to onset of SCI among individuals who had relatively low-normal cognitive function $(24 \leq \mathrm{K}-\mathrm{MMSE}$ score $\leq 26)$ at baseline. Meanwhile, non-problematic drinking, compared with abstinence, appeared to be protective against the development of SCI, and to be related to a slow decline in cognitive function among men.

Previous studies have shown inconsistent evidence of worse cognitive performance in heavy drinkers and beneficial cognitive function in moderate drinkers. Studies in the USA reported that adults with a history of alcohol use disorders at baseline suffered severe memory impairment. ${ }^{9}{ }^{10}$ By contrast, in Eastern European countries, heavy, binge, and problematic drinking at baseline were not consistently associated with cognitive function. ${ }^{7}$ This difference may be related to difference in cognitive function at baseline or follow-up period. According to our results, while history of problematic drinking was related to faster decline in cognitive performance, people within a normal range but relatively low levels of cognitive function at baseline were at higher risk of development of SCI 6 years later. That is, while problematic drinking may be associated with faster decline in cognitive function ${ }^{6}$ and, consequently, higher risk of cognitive impairment, the onset of SCI may not be observed in a short period.

Meanwhile, in the current study, beneficial effects of moderate non-problematic drinking were observed 
Table 2 Association of baseline alcohol drinking status with severe cognitive impairment after 6 years' follow-up among Korean adults aged $\geq 45$ years

\begin{tabular}{|c|c|c|c|c|c|}
\hline & \multicolumn{4}{|c|}{ Baseline alcohol drinking status } & \multirow[b]{2}{*}{ OR for trend } \\
\hline & No alcohol drinking & Past alcohol drinking & $\begin{array}{l}\text { Non-problematic } \\
\text { alcohol drinking }\end{array}$ & $\begin{array}{l}\text { Problematic } \\
\text { alcohol drinking }\end{array}$ & \\
\hline All $(\mathrm{N}=5157)$ & $(\mathrm{N}=2597, \mathrm{n}=204)$ & $(\mathrm{N}=296, \mathrm{n}=24)$ & $(\mathrm{N}=2071, \mathrm{n}=118)$ & $(\mathrm{N}=193, \mathrm{n}=15)$ & \\
\hline Model 1: adjusted OR (95\% Cl) & 1.26 (0.93 to 1.72$)$ & $1.02(0.63$ to 1.66$)$ & 1.00 & $1.69^{+}(0.91$ to 3.17$)$ & $0.94(0.81$ to 1.11$)$ \\
\hline Model 2: adjusted OR $(95 \% \mathrm{Cl})$ & $1.26(0.93$ to 1.72$)$ & $0.98(0.60$ to 1.60$)$ & 1.00 & $1.69(0.90$ to 3.18$)$ & $0.94(0.81$ to 1.11$)$ \\
\hline Model 3: adjusted OR $(95 \% \mathrm{Cl})$ & $1.27(0.93$ to 1.73$)$ & 0.95 (0.58 to 1.55$)$ & 1.00 & $1.67(0.89$ to 3.14$)$ & $0.94(0.80$ to 1.10$)$ \\
\hline Model 4: adjusted OR $(95 \% \mathrm{Cl})$ & $1.27(0.93$ to 1.74$)$ & 0.89 (0.55 to 1.45$)$ & 1.00 & 1.60 (0.85 to 3.04$)$ & $0.94(0.80$ to 1.10$)$ \\
\hline Baseline K-MMSE 24-26 ( $\mathrm{N}=1564)$ & $(\mathrm{N}=854, \mathrm{n}=92)$ & $(N=111, n=13)$ & $(\mathrm{N}=546, \mathrm{n}=40)$ & $(\mathrm{N}=53, \mathrm{n}=9)$ & \\
\hline Model 1: adjusted OR $(95 \% \mathrm{Cl})$ & $1.14(0.72$ to 1.81$)$ & 1.41 (0.68 to 2.93 ) & 1.00 & $4.12^{* *}(1.65$ to 10.32$)$ & $1.09(0.87$ to 1.37$)$ \\
\hline Model 2: adjusted OR (95\% Cl) & $1.16(0.71$ to 1.89$)$ & 1.51 (0.72 to 3.17$)$ & 1.00 & $4.43^{* *}$ (1.75 to 11.23$)$ & 1.09 (0.86 to 1.37$)$ \\
\hline Model 3: adjusted OR $(95 \% \mathrm{Cl})$ & $1.20(0.73$ to 1.98$)$ & 1.37 (0.66 to 2.83$)$ & 1.00 & $4.13^{* *}$ (1.65 to 10.32$)$ & $1.06(0.84$ to 1.35$)$ \\
\hline Model 4: adjusted OR $(95 \% \mathrm{Cl})$ & $1.21(0.72$ to 2.01$)$ & $1.30(0.62$ to 2.71$)$ & 1.00 & $3.76^{* *}$ (1.46 to 9.67$)$ & $1.05(0.82$ to 1.35$)$ \\
\hline Baseline K-MMSE 27-30 ( $\mathrm{N}=3593)$ & $(\mathrm{N}=1743, \mathrm{n}=112)$ & $(\mathrm{N}=185, \mathrm{n}=11)$ & $(\mathrm{N}=1525, \mathrm{n}=78)$ & $(N=140, n=6)$ & \\
\hline Model 1: adjusted OR $(95 \% \mathrm{Cl})$ & 1.34 (0.90 to 2.00$)$ & $0.82(0.41$ to 1.66$)$ & 1.00 & $0.92(0.37$ to 2.31$)$ & $0.87(0.72$ to 1.06$)$ \\
\hline Model 2: adjusted OR (95\% Cl) & $1.32(0.89$ to 1.97$)$ & 0.74 (0.37 to 1.51$)$ & 1.00 & 0.89 (0.35 to 2.27$)$ & $0.88(0.72$ to 1.06$)$ \\
\hline Model 3: adjusted OR $(95 \% \mathrm{Cl})$ & 1.29 (0.87 to 1.92$)$ & 0.74 (0.36 to 1.50$)$ & 1.00 & 0.91 (0.36 to 2.33$)$ & $0.89(0.73$ to 1.08$)$ \\
\hline Model 4: adjusted OR $(95 \% \mathrm{Cl})$ & $1.29(0.87$ to 1.92$)$ & 0.69 ( 0.35 to 1.39$)$ & 1.00 & 0.90 (0.35 to 2.31$)$ & $0.89(0.73$ to 1.08$)$ \\
\hline
\end{tabular}

1.29 (0.87 to 1.92$)$

$0.69(0.35$ to 1.39$)$

$0.90(0.35$ to 2.31$)$

$\mathrm{N}=$ number of observations; $n=$ number of cases of cognitive impairment (K-MMSE $\leq 17$ in 2012).

Results of multiple logistic regressions. For Korean adults aged $\geq 45$ years with normal baseline cognitive function (K-MMSE $\geq 24$ ), alcohol drinking status at baseline (reference: non-problematic

drinking) and development of severe cognitive impairment after 6 years of follow-up (K-MMSE $\leq 17$ ) were measured from the 2006 survey and the 2012 survey, respectively.

Model 1 adjusted for gender and age at baseline (2006 survey).

Model 2 added marital status, health insurance, income, educational level and living place at baseline based on model 1.

Model 3 added exercise, smoking status and comorbidity at baseline based on model 2.

Model 4 added baseline K-MMSE score, ADL and depression at baseline based on model 3.

${ }^{* * *} \mathrm{p}<0.001,{ }^{* *} p<0.01,{ }^{*} p<0.05,{ }^{+} p<0.1$

K-MMSE, Korean Mini-Mental State Examination. 


\begin{tabular}{|c|c|c|c|c|c|}
\hline & \multicolumn{4}{|c|}{ Baseline alcohol drinking status } & \multirow[b]{2}{*}{ OR for trend } \\
\hline & No alcohol drinking & Past alcohol drinking & $\begin{array}{l}\text { Non-problematic } \\
\text { alcohol drinking }\end{array}$ & $\begin{array}{l}\text { Problematic alcohol } \\
\text { drinking }\end{array}$ & \\
\hline Men $(\mathrm{N}=2528)$ & $(\mathrm{N}=583, \mathrm{n}=54)$ & $(\mathrm{N}=258, \mathrm{n}=19)$ & $(\mathrm{N}=1511, \mathrm{n}=86)$ & $(\mathrm{N}=176, \mathrm{n}=13)$ & \\
\hline Adjusted OR (95\% Cl) & $1.62^{*}(1.09$ to 2.39$)$ & $0.75(0.42$ to 1.35$)$ & 1.00 & $1.74(0.86$ to 3.53$)$ & $0.88(0.71$ to 1.09$)$ \\
\hline Women $(\mathrm{N}=2629)$ & $(\mathrm{N}=2014, \mathrm{n}=150)$ & $(\mathrm{N}=38, \mathrm{n}=5)$ & $(\mathrm{N}=560, \mathrm{n}=32)$ & $(\mathrm{N}=17, \mathrm{n}=2)$ & \\
\hline Adjusted OR $(95 \% \mathrm{Cl})$ & $1.00(0.65$ to 1.53$)$ & $1.63(0.57$ to 4.63$)$ & 1.00 & $1.79(0.40$ to 8.08$)$ & $1.03(0.83$ to 1.26$)$ \\
\hline Ever smoker $(\mathrm{N}=1632)$ & $(\mathrm{N}=273, \mathrm{n}=25)$ & $(\mathrm{N}=170, \mathrm{n}=15)$ & $(\mathrm{N}=1036, \mathrm{n}=60)$ & $(\mathrm{N}=153, \mathrm{n}=11)$ & \\
\hline Adjusted OR (95\% Cl) & $1.20(0.66$ to 2.17$)$ & $0.89(0.45$ to 1.76$)$ & 1.00 & $1.52(0.68$ to 3.40$)$ & $1.02(0.77$ to 1.36$)$ \\
\hline Never smoker $(\mathrm{N}=3525)$ & $(\mathrm{N}=2324, \mathrm{n}=18)$ & $(\mathrm{N}=126, \mathrm{n}=7)$ & $(\mathrm{N}=1035, \mathrm{n}=37)$ & $(\mathrm{N}=40, \mathrm{n}=8)$ & \\
\hline Adjusted OR $(95 \% \mathrm{Cl})$ & $1.28(0.89$ to 1.83$)$ & $0.81(0.37$ to 1.76$)$ & 1.00 & 1.79 (0.65 to 4.97$)$ & $0.91(0.76$ to 1.09$)$ \\
\hline No exercise $(\mathrm{N}=2277)$ & $(\mathrm{N}=1090, \mathrm{n}=125)$ & $(\mathrm{N}=143, \mathrm{n}=15)$ & $(\mathrm{N}=954, \mathrm{n}=65)$ & $(\mathrm{N}=90, \mathrm{n}=9)$ & \\
\hline Adjusted OR (95\% Cl) & $1.38(0.91$ to 2.09$)$ & 0.91 (0.49 to 1.69$)$ & 1.00 & 1.50 (0.68 to 3.32$)$ & $0.90(0.73$ to 1.10$)$ \\
\hline Exercise $(\mathrm{N}=2880)$ & $(\mathrm{N}=1507, \mathrm{n}=79)$ & $(\mathrm{N}=153, \mathrm{n}=9)$ & $(\mathrm{N}=1117, \mathrm{n}=53)$ & $(\mathrm{N}=103, \mathrm{n}=6)$ & \\
\hline Adjusted OR $(95 \% \mathrm{Cl})$ & $1.10(0.74$ to 1.62$)$ & $0.94(0.43$ to 2.04$)$ & 1.00 & $1.74(0.63$ to 4.80$)$ & $1.01(0.83$ to 1.24$)$ \\
\hline $\mathrm{BMI} \geq 25(\mathrm{~N}=1226)$ & $(\mathrm{N}=624, \mathrm{n}=39)$ & $(\mathrm{N}=70, \mathrm{n}=5)$ & $(\mathrm{N}=491, \mathrm{n}=22)$ & $(\mathrm{N}=41, \mathrm{n}=1)$ & \\
\hline Adjusted OR $(95 \% \mathrm{Cl})$ & $2.11(0.99$ to 4.50$)$ & $1.36(0.43$ to 4.27$)$ & 1.00 & $0.97(0.12$ to 8.13$)$ & $0.70+(0.49$ to 1.01$)$ \\
\hline $\mathrm{BMl}<25(\mathrm{~N}=3899)$ & $(\mathrm{N}=1958, \mathrm{n}=163)$ & $(\mathrm{N}=223, \mathrm{n}=19)$ & $(\mathrm{N}=1568, \mathrm{n}=95)$ & $(\mathrm{N}=150, \mathrm{n}=14)$ & \\
\hline Adjusted OR $(95 \% \mathrm{Cl})$ & $1.11(0.77$ to 1.59$)$ & $0.81(0.47$ to 1.37$)$ & 1.00 & $1.75(0.87$ to 3.51$)$ & $1.02(0.85$ to 1.21$)$ \\
\hline Age $\geq 65(N=1343)$ & $(\mathrm{N}=713, \mathrm{n}=110)$ & $(\mathrm{N}=136, \mathrm{n}=19)$ & $(\mathrm{N}=457, \mathrm{n}=49)$ & $(\mathrm{N}=37, \mathrm{n}=7)$ & \\
\hline Adjusted OR $(95 \% \mathrm{Cl})$ & 1.47 (0.92 to 2.35$)$ & $1.38(0.77$ to 2.46$)$ & 1.00 & $2.23(0.90$ to 5.50$)$ & $0.89(0.71$ to 1.11$)$ \\
\hline Age $<65(\mathrm{~N}=3814)$ & $(\mathrm{N}=1884, \mathrm{n}=94)$ & $(\mathrm{N}=160, \mathrm{n}=5)$ & $(\mathrm{N}=1614, \mathrm{n}=69)$ & $(\mathrm{N}=156, \mathrm{n}=8)$ & \\
\hline Adjusted OR $(95 \% \mathrm{Cl})$ & $1.21(0.80$ to 1.83$)$ & $0.58(0.22$ to 1.51$)$ & 1.00 & $1.42(0.64$ to 3.13$)$ & $0.96(0.78$ to 1.18$)$ \\
\hline Education $\geq$ college $(\mathrm{N}=2399)$ & $(\mathrm{N}=1063, \mathrm{n}=70)$ & $(\mathrm{N}=118, \mathrm{n}=6)$ & $(\mathrm{N}=1128, \mathrm{n}=55)$ & $(\mathrm{N}=90, \mathrm{n}=7)$ & \\
\hline Adjusted OR $(95 \% \mathrm{Cl})$ & $1.46(0.92$ to 2.32$)$ & $0.60(0.22$ to 1.58$)$ & 1.00 & $1.70(0.64$ to 4.49$)$ & $0.89(0.71$ to 1.12$)$ \\
\hline Education<college $(\mathrm{N}=2758)$ & $(\mathrm{N}=1534, \mathrm{n}=134)$ & $(\mathrm{N}=178, \mathrm{n}=18)$ & $(\mathrm{N}=943, \mathrm{n}=63)$ & $(\mathrm{N}=103, \mathrm{n}=8)$ & \\
\hline Adjusted OR (95\% Cl) & $1.17(0.77$ to 1.76$)$ & $1.06(0.60$ to 1.87$)$ & 1.00 & $1.50(0.65$ to 3.47$)$ & 0.97 (0.79 to 1.19$)$ \\
\hline Top $50 \%$ of income $(\mathrm{N}=2578)$ & $(\mathrm{N}=1271 \mathrm{n}=69)$ & $(N=138, n=14)$ & $(\mathrm{N}=1069, \mathrm{n}=48)$ & $(\mathrm{N}=100, \mathrm{n}=6)$ & \\
\hline Adjusted OR $(95 \% \mathrm{Cl})$ & $1.23(0.77$ to 1.97$)$ & $1.32(0.68$ to 2.58$)$ & 1.00 & $1.92(0.77$ to 4.75$)$ & $0.96(0.75$ to 1.23$)$ \\
\hline Bottom $50 \%$ of income $(\mathrm{N}=2579)$ & $(\mathrm{N}=1326, \mathrm{n}=135)$ & $(\mathrm{N}=158, \mathrm{n}=10)$ & $(\mathrm{N}=1002, \mathrm{n}=70)$ & $(\mathrm{N}=93, \mathrm{n}=9)$ & \\
\hline Adjusted OR (95\% Cl) & $1.32(0.87$ to 2.00$)$ & $0.57(0.28$ to 1.17$)$ & 1.00 & $1.36(0.55$ to 3.37$)$ & 0.91 (0.75 to 1.12$)$ \\
\hline Living urban areas $(\mathrm{N}=3965)$ & $(\mathrm{N}=2014, \mathrm{n}=150)$ & $(\mathrm{N}=213, \mathrm{n}=15)$ & $(\mathrm{N}=1601, \mathrm{n}=97)$ & $(\mathrm{N}=137, \mathrm{n}=13)$ & \\
\hline Adjusted OR $(95 \% \mathrm{Cl})$ & $1.11(0.78$ to 1.58$)$ & $0.75(0.41$ to 1.39$)$ & 1.00 & $1.68(0.82$ to 3.45$)$ & $1.01(0.84$ to 1.21$)$ \\
\hline Living rural areas $(\mathrm{N}=1192)$ & $(\mathrm{N}=583, \mathrm{n}=54)$ & $(\mathrm{N}=83, \mathrm{n}=9)$ & $(\mathrm{N}=470, \mathrm{n}=21)$ & $(\mathrm{N}=56, \mathrm{n}=2)$ & \\
\hline Adjusted OR $(95 \% \mathrm{Cl})$ & $2.07^{*}$ (1.08 to 3.99$)$ & 1.67 (0.82 to 3.38$)$ & 1.00 & $1.44(0.30$ to 6.99$)$ & $0.74+(0.54$ to 1.01$)$ \\
\hline Chronic disease: $0(\mathrm{~N}=3026)$ & $(\mathrm{N}=1507, \mathrm{n}=102)$ & $(\mathrm{N}=111, \mathrm{n}=5)$ & $(\mathrm{N}=1298, \mathrm{n}=66)$ & $(\mathrm{N}=110, \mathrm{n}=3)$ & \\
\hline Adjusted OR (95\% Cl) & 1.45 (0.91 to 2.29$)$ & $0.48(0.19$ to 1.24$)$ & 1.00 & $0.48(0.14$ to 1.65$)$ & $0.82+(0.65$ to 1.02$)$ \\
\hline Chronic disease: $1+(\mathrm{N}=2131)$ & $(\mathrm{N}=1090, \mathrm{n}=102)$ & $(\mathrm{N}=185, \mathrm{n}=19)$ & $(\mathrm{N}=773, \mathrm{n}=52)$ & $(\mathrm{N}=83, \mathrm{n}=12)$ & \\
\hline Adjusted OR $(95 \% \mathrm{Cl})$ & $1.10(0.70$ to -1.71$)$ & $1.16(0.64$ to 2.13$)$ & 1.00 & $3.60^{* *}(1.61$ to 8.07$)$ & $1.10(0.89$ to 1.37$)$ \\
\hline
\end{tabular}


among men, showing that abstainers, more than nonproblematic drinkers, experienced a higher risk of SCI and more rapid decline in cognitive function. While the protective effects of light-moderate alcohol intake have been reported against cognitive impairment, ${ }^{20}{ }^{21}$ those beneficial associations were sometimes observed limitedly in specific populations, such as women, but not men, and people with MCI at baseline. ${ }^{3-6} 22$ It is unknown which factors (ie, different lifestyle or drinking practices) cause those different relationships.

Several mechanisms have been identified to be associated with the links of alcohol drinking behaviours to cognitive impairment. Compared with light to moderate non-problematic drinkers, abstinence and PrAD are associated with higher risk of vascular disease, which may increase the risk of cognitive impairment; that is, vascular dementia. ${ }^{23}$ Problematic alcohol drinking is also directly related to abnormalities in brain morphology, regional cerebral blood flow and brain trauma. ${ }^{34}{ }^{25}$ Furthermore, PrAD combined with other risk factors may be more significantly tied to cognitive impairment. Chronic diseases are known to be directly and indirectly related to cognitive impairment. For example, hypertension, diabetes mellitus and hyperlipidaemia are linked to vascular damage which results in cognitive impairment; ${ }^{26} 27$ and more directly, abnormal insulin regulation of type 2 diabetes is likely related to cognitive impairment. ${ }^{27}$ Indeed, our results show that PrAD is more detrimental to cognitive function in an individual with chronic disease.

There are several limitations of this study. First, we used a self-reported measure of alcohol drinking behaviour. It is possible that participants under-report (or over-report) their drinking behaviours. ${ }^{28}$ Second, longitudinal studies may have a common issue of selection bias due to differential loss to follow-up. Among 7299 participants with normal cognitive function in 2006, $71 \%$ were included in the study population, $29 \%$ were eliminated due to death, non-responses and missing values. However, the mean values of K-MMSE score at baseline did not differ between two groups (study population: mean=25.12; dropouts: mean=25.23). Therefore, the sample attrition might not have influenced our findings. Last, due to the small sample size for PrAD among women $(\mathrm{N}=17)$, we were able to observe only two cases of SCI among women with PrAD at baseline, resulting in a non-significant result. We should be careful in translating the findings.

Despite the limitations, there are several strengths of our present study. First, we used a nationally representative prospective survey. Therefore, the findings from our analysis might be generalisable to the population of Korean adults aged 45 years or older. Particularly, the results from subgroup analyses could provide evidence of necessities of targeted strategy for the prevention of dementia related to alcohol drinking, focusing on specific subpopulations including those with low-normal cognitive function $(24 \leq \mathrm{K}-\mathrm{MMSE} \leq 26)$. Second, in order to address the issue of reverse causation in observational studies, we limited study participants to those with normal cognitive function at baseline (K-MMSE $\geq 26$ ), and investigated the association of drinking behaviours with the outcomes of SCI (K-MMSE $\leq 17)$ and change in cognitive function over the 6 years of follow-up after adjusting for baseline K-MMSE scores as well as all other covariates. Therefore, the findings could be, to some extent, robust toward resolving the potential issue of reverse causation. Third, this study assessed the relationship between a history of alcohol use disorders and cognitive function, by employing the CAGE questionnaire which is a validated and widely used screening instrument for alcohol use disorders. ${ }^{29}$ Furthermore, findings from this study show that the CAGE questionnaire could be used as a practical measure to identify individuals at risk of alcoholrelated cognitive impairment.

In conclusion, our prospective study shows that a history of problematic alcohol use was a risk factor for rapid cognitive decline as well as the development of SCI, while the protective effects of non-problematic drinking were observed among men. Since the associations may vary across different populations and measurements, caution should also be exercised extrapolating these conclusions. In the future, the detrimental consequences of alcohol on cognitive performance would need to be assessed from a multifactorial perspective. While further research will provide stronger evidence as well as more insight into the relationship between alcohol consumption and cognitive impairment/ decline, intervention for individuals with problematic alcohol use behaviour may play a role in prevention of cognitive impairment.

Contributors SMP and SK. conceptualised the study. SK conducted the statistical analysis. SK and YK wrote the first draft of the manuscript. All authors contributed to interpretation of results and revisions of the manuscript.

Funding This research received no specific grant from any funding agency in the public, commercial or not-for-profit sectors.

Competing interests None declared.

Provenance and peer review Not commissioned; externally peer reviewed.

Data sharing statement No additional data are available.

Open Access This is an Open Access article distributed in accordance with the Creative Commons Attribution Non Commercial (CC BY-NC 4.0) license, which permits others to distribute, remix, adapt, build upon this work noncommercially, and license their derivative works on different terms, provided the original work is properly cited and the use is non-commercial. See: http:// creativecommons.org/licenses/by-nc/4.0/

\section{REFERENCES}

1. Mathers CD, Loncar D. Projections of global mortality and Burden of disease from 2002 to 2030. PLoS Med 2006;3:e442.

2. World Health Organization. Dementia: a public health priority. Geneva: World Health Organization, 2012.

3. Davis BJ, Vidal JS, Garcia M, et al. The alcohol paradox: light-to-moderate alcohol consumption, cognitive function, and brain volume. J Gerontol A Biol Sci Med Sci 2014;69:1528-35.

4. Almeida OP, Hankey GJ, Yeap BB, et al. Alcohol consumption and cognitive impairment in older men: a mendelian randomization study. Neurology 2014;82:1038-44. 
5. Solfrizzi V, D'Introno A, Colacicco AM, et al. Alcohol consumption, mild cognitive impairment, and progression to dementia. Neurology 2007;68:1790-9.

6. Sabia S, Elbaz A, Britton A, et al. Alcohol consumption and cognitive decline in early old age. Neurology 2014;82:332-9.

7. Horvat $\mathrm{P}$, Richards M, Kubinova R, et al. Alcohol consumption, drinking patterns, and cognitive function in older Eastern European adults. Neurology 2015;84:287-95.

8. Park B, Park J, Jun JK, et al. Gender differences in the association of smoking and drinking with the development of cognitive impairment. PLOS ONE 2013;8:e75095.

9. Kuźma E, Llewellyn DJ, Langa KM, et al. History of alcohol use disorders and risk of severe cognitive impairment: a 19-year prospective cohort study. Am J Geriatr Psychiatry 2014;22:1047-54

10. Perreira KM, Sloan FA. Excess alcohol consumption and health outcomes: a 6-year follow-up of men over age 50 from the health and retirement study. Addiction 2002;97:301-10.

11. Bühler M, Mann K. Alcohol and the human brain: a systematic review of different neuroimaging methods. Alcohol Clin Exp Res 2011;35:1771-93.

12. Harper $\mathrm{C}$. The neuropathology of alcohol-related brain damage. Alcohol Alcohol 2009;44:136-40.

13. World Health Organization. Global status report on alcohol and health 2014. Geneva: World Health Organization, 2014.

14. Lee HK, Chou SP, Cho MJ, et al. The prevalence and correlates of alcohol use disorders in the United States and Korea-a cross-national comparative study. Alcohol 2010;44:297-306.

15. Korea Employment Information Service. User's Guide: 4th Korean longitudinal study of ageing. Umsung: Korea Employment Information Service. 2013.

16. Folstein MF, Folstein SE, McHugh PR. "Mini-mental state". A practical method for grading the cognitive state of patients for the clinician. J Psychiatr Res 1975;12:189-98.

17. Kang $Y, \mathrm{Na} D L$, Hahn $\mathrm{S}$. A validity study on the Korean Mini-Mental State Examination (K-MMSE) in dementia patients. J Korean Neurol Association 1997;15:300-8.
18. Ewing JA. Detecting alcoholism. The CAGE questionnaire. JAMA 1984;252:1905-7.

19. Kohout FJ, Berkman LF, Evans DA, et al. Two shorter forms of the CES-D Depression Symptoms Index. J Aging Health 1993:5:179-93.

20. Peters R, Peters J, Warner J, et al. Alcohol, dementia and cognitive decline in the elderly: a systematic review. Age Ageing 2008;37:505-12.

21. Anstey KJ, Mack HA, Cherbuin N. Alcohol consumption as a risk factor for dementia and cognitive decline: meta-analysis of prospective studies. Am J Geriatr Psychiatry 2009;17:542-55.

22. Hogenkamp PS, Benedict C, Sjögren P, et al. Late-life alcohol consumption and cognitive function in elderly men. Age (Dordr) 2014;36:243-9.

23. Rehm J, Sempos CT, Trevisan M. Alcohol and cardiovascular disease--more than one paradox to consider. Average volume of alcohol consumption, patterns of drinking and risk of coronary heart disease--a review. J Cardiovasc Risk 2003;10:15-20.

24. Panza F, Frisardi V, Seripa D, et al. Alcohol consumption in mild cognitive impairment and dementia: harmful or neuroprotective? Int $J$ Geriatr Psychiatry 2012;27:1218-38.

25. Brust JC. Ethanol and cognition: indirect effects, neurotoxicity and neuroprotection: a review. Int J Environ Res Public Health 2010;7:1540-57.

26. Etgen $\mathrm{T}$, Sander $\mathrm{D}$, Bickel $\mathrm{H}$, et al. Mild cognitive impairment and dementia: the importance of modifiable risk factors. Dtsch Arztebl Int 2011;108:743-50.

27. Okereke OI, Kang JH, Cook NR, et al. Type 2 diabetes mellitus and cognitive decline in two large cohorts of community-dwelling older adults. J Am Geriatr Soc 2008;56:1028-36.

28. Lyu J, Lee SH. Alcohol consumption and cognitive impairment among Korean older adults: does gender matter? Int Psychogeriatr 2014;26:335-40.

29. Buchsbaum DG, Buchanan RG, Centor RM, et al. Screening for alcohol abuse using CAGE scores and likelihood ratios. Ann Intern Med 1991;115:774-7. 